\title{
Noncovalent Interactions in $o$-Fluorinated Post-titanocene Living Ethylene Polymerization Catalyst
}

\author{
Konstantin P. Bryliakov, ${ }^{*}{ }^{\dagger}$ Evgenii P. Talsi, ${ }^{\dagger}$ Heiko M. Möller, \\ Moritz C. Baier, ${ }^{*}$ and Stefan Mecking*, \\ ${ }^{\dagger}$ Boreskov Institute of Catalysis, Pr. Lavrentieva 5, 630090 Novosibirsk, Russian Federation, and \\ *University of Konstanz, Chair of Chemical Material Science, Department of Chemistry, \\ Universitätstrasse 10, D-78457 Konstanz, Germany
}

Received July 26, 2010

Summary: Multinuclear NMR spectroscopic studies of polymerization-active species generated by activation of $o-F$-substituted and nonsubstituted bis(enolatoimine) titanium complexes with MAO evidence a noncovalent interaction of the o-F moieties with the metal center, which is likely to facilitate living ethylene polymerization via suppression of chain transfer and of $\beta$-hydrogen transfer processes.

Catalytic insertion polymerization of olefins is unsurpassed by other polymerization methods in terms of microstructure control. However, living catalytic polymerizations are challenging because of the process of chain termination by $\beta$-H elimination or polymeryl transfer to cocatalyst. A remarkably versatile and robust catalyst system for the living polymerization of ethylene and propene was found with certain phenoxyimine $\mathrm{Ti}$ complexes, as reported by the groups of Fujita ${ }^{1 \mathrm{a}}$ and of Coates. ${ }^{1 \mathrm{~b}}$ Considerable efforts were directed toward understanding the origin of its living nature. From investigations on a series of bis(phenoxyimine) titanium catalysts, Fujita and co-workers ascribed the key role for the living behavior to $o$-F substitution in the $\mathrm{N}$-bound aryl rings. ${ }^{2}$ On the basis of DFT calculations, they suggested that formation of a hydrogen bond between an $o$-F atom and the $\beta$-hydrogen atom of the growing polymer chain suppresses $\beta$-hydrogen elimination and polymeryl transfer to the cocatalysts. ${ }^{2 a, b}$ Since then, possible effects of weak ligand polymer interactions on the polymerization processes have been debated controversially. ${ }^{3}$ For example, Talarico and co-workers suggested that weak repulsive interactions between $o-\mathrm{F}$ atoms and the growing polymer chain might be responsible for living propene polymerization

*To whom correspondence should be addressed. E mail: bryliako@ catalysis.ru; stefan.mecking@uni konstanz.de.

(1) (a) Saito, J.; Mitani, M.; Mohri, J.; Yoshida, Y : Matsui, S.; Ishii, S.; Kojoh, S.; Kashiwa, N.; Fujita, T. Angew. Chem., Int. Ed. 2001, 40, 2918 2920. (b) Tian, J.; Hustad, P. D.; Coates, G. W. J. Am. Chem. Soc. 2001, 123, 51345135.

(2) (a) Mitani, M.; Mohri, J.; Yoshida, Y.; Saito, J.; Ishii, S.; Tsuru, K.; Matsui, S.; Furuyama, R.; Nakano, T.; Tanaka, H.; Kojoh, S.; Matsugi, T.; Kashiwa, N.; Fujita, T. J. Am. Chem. Soc. 2002, 124, 3327 3336. (b) Mitani, M.; Nakano, T.; Fujita, T. Chem.-Eur. J. 2003, 9, 2396 2403. (c) Furuyama, R.; Mitani, M.; Mohri, J.; Mori, R.; Tanaka, H.; Fujita, T. Macromolecules 2005, 38, 1546 1552. (d) Furuyama, R.; Saito, J.; Ishii, S.; Makio, H.; Mitani, M.; Tanaka, H.; Fujita, T. J. Organomet. Chem. 2005, 690, 4398 4413. (e) Makio, H.; Fujita, T. Acc. Chem. Res. 2009, 42, 1532 1544.

(3) (a) Chan, M. C. W. Chem. Asian J. 2008, 3, 18 27. (b) Kui, S. C. F.; Zhu, N.; Chan, M. C. W. Angew. Chem., Int. Ed. 2003, 42, 1628 1632. (c) Chan, M. C. W.; Kui, S. C. F.; Cole, J. M.; McIntyre, G. J.; Matsui, S.; Zhu, N.; Tam, K. H. Chem.-Eur. J. 2006, 12, 2607 2619. (d) Talarico, G.; Busico, V.; Cavallo, L. Organometallics 2004, 23, 59895993. behavior of $o$-fluorinated bis(phenoxyimine) titanium catalysts. $^{3 \mathrm{~d}}$

Recently, the new $o$-F-substituted bis(enolatoimine) titanium complex 1a was found to induce living olefin polymerization in the presence of methylalumoxane (MAO) at hitherto unattainably high temperatures and afford polyethylenes with unprecedented narrow molecular weight distributions and high molecular weights at the same time $\left(M_{\mathrm{w}} /\right.$ $\left.M_{\mathrm{n}} 1.01, M_{\mathrm{n}} 3 \times 10^{5} \mathrm{~g} \mathrm{~mol}^{1}\right),{ }^{4 \mathrm{a}}$ while its unsubstituted counterpart $\mathbf{1 b}^{4 \mathrm{~b}}$ displayed nonliving behavior. This high stability toward $\beta$-hydrogen elimination and chain transfer ${ }^{5}$ encouraged us to undertake a mechanistic study, with special focus on the role of $o$-F substituents, based on the approach previously used to probe the activation of titanium phenoxyimine complexes in the presence of MAO and boron-based activators. $^{6}$

Both 1a and $\mathbf{1 b}$ were found to interact with MAO in a similar manner (Scheme 1) to yield mainly the monomethylated species $\mathrm{L}_{2} \mathrm{TiClMe}$ at low cocatalyst loadings (Al:Ti $<5)$ and ion pairs $\left[\mathrm{L}_{2} \mathrm{TiMe}\right]^{+}[\mathrm{MeMAO}]$ at higher loadings $(\mathrm{Al}: \mathrm{Ti}>25$; for spectroscopic characterization of these intermediates see the Supporting Information, SI). For the identification of cationic species in metallocene and postmetallocene olefin polymerization catalysts, the detection of methyl groups bound to the metal is crucial. This is sometimes complicated by exchange line broadening and by bonding to nonuniform MAO oligomers. ${ }^{6 c, 7}$ Fortunately, the use of ${ }^{13} \mathrm{C}-\mathrm{MAO}^{6 \mathrm{c}, 7 \mathrm{c}, 7 \mathrm{~d}}\left(60 \%{ }^{13} \mathrm{C}\right.$ enrichment $)$ allowed the unambiguous assignment of terminal $\mathrm{Ti}^{13} \mathrm{CH}_{3}$ groups in $\mathbf{2}$ and 3, thus ruling out any heterobinuclear or zwitterion-like

(4) (a) Yu, S. M.; Mecking, S. J. Am. Chem. Soc. 2008, 130, 13204 13205. (b) Li, X. F.; Dai, K.; Ye, W. P.; Pan, L.; Li, Y. S. Organometallics 2004, 23, 12231230.

(5) It is apparent that $\beta$ hydrogen elimination (via transfer either to the metal or to the monomer) can make only a minor contribution to the chain termination in ethylene polymerization over bis(enolatoimine) titanium catalysts (since saturated end linear PE was found to form for both $\mathbf{1 a}$ and $\mathbf{1 b}$ ), whereas transfer to $\mathrm{AlMe}_{3}$ is the major chain termina tion pathway.

(6) (a) Makio, H.; Fujita, T. Macromol. Symp. 2004, 213, 221 233. (b) Makio, H.; Oshiki, T.; Takai, K.; Fujita, T. Chem. Lett. 2005, 1382 1383. (c) Bryliakov, K. P.; Kravtsov, E. A.; Pennington, D. A.; Lancaster, S. J.; Bochmann, M.; Brintzinger, H. H.; Talsi, E. P. Organometallics 2005, 24 , 5660 5664. (d) Bryliakov, K. P.; Kravtsov, E. A.; Broomfield, L.; Talsi, E. P.; Bochmann, M. Organometallics 2007, 26, 288293.

(7) (a) Bochmann, M.; Lancaster, S. J. Angew. Chem., Int. Ed. Engl. 1994, 33, 1634 1637. (b) Tritto, I.; Sacchi, M. C.; Locatelli, P.; Li, S. X. Macromol. Symp. 1995, 89, 289 298. (c) Babushkin, D. E.; Semikolenova, N. V.; Zakharov, V. A.; Talsi, E. P. Macromol. Chem. Phys. 2000, 201, 558 567. (d) Bryliakov, K. P.; Talsi, E. P.; Bochmann, M. Organometallics 2004, 23,149152 
Scheme 1. Activation of Complexes 1a and 1b with MAO



(1a) $R=F$ (1b) $\mathrm{R}=\mathrm{H}$

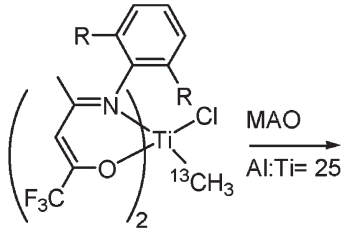

(2a) $R=F$ (2b) $R=H$

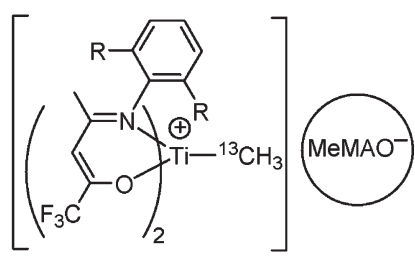

(3a) $R=F$
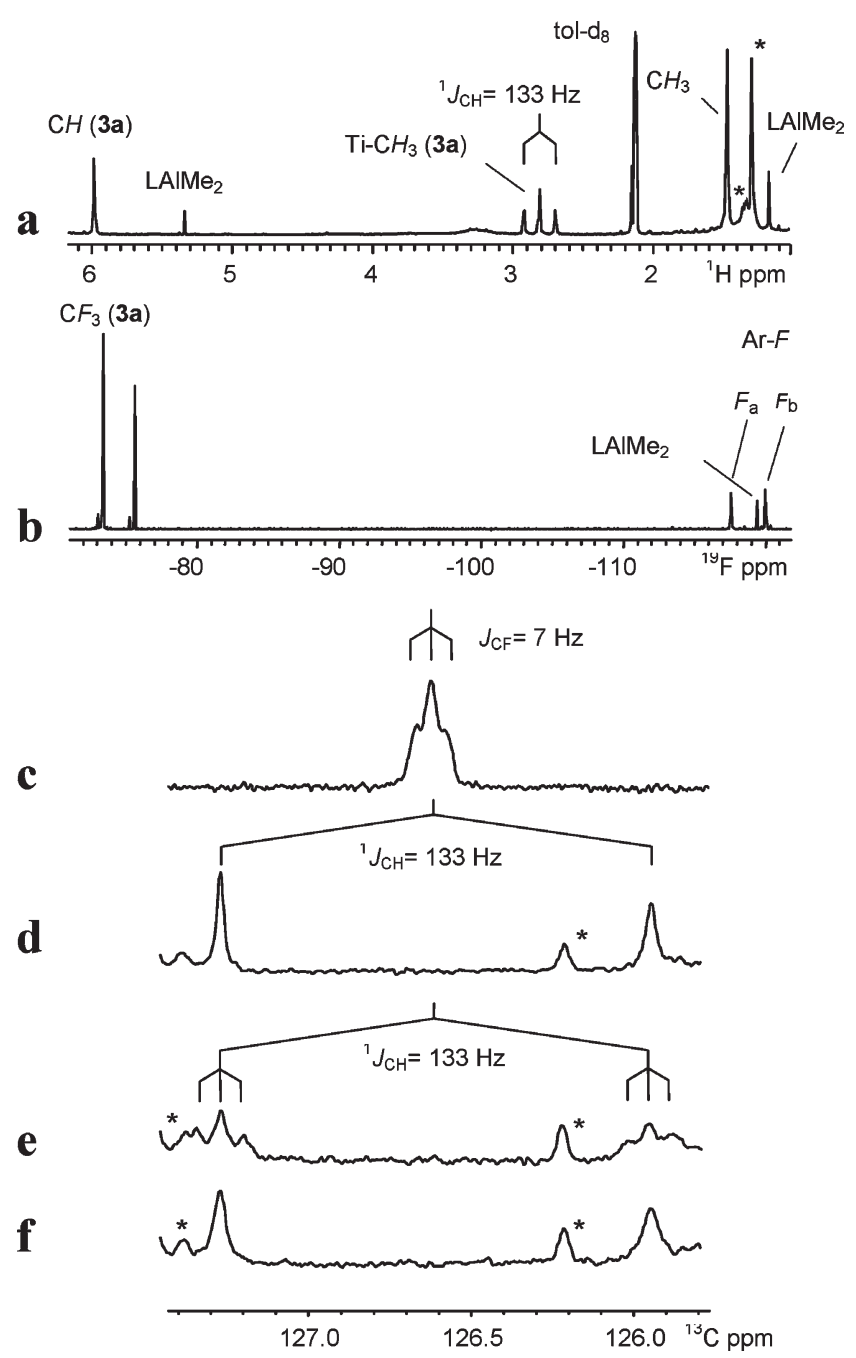

Figure 1. NMR spectra of 3a generated by the reaction of $\mathbf{1 a}$ with ${ }^{13} \mathrm{C}$ MAO ([1a] $2 \times 10^{2} \mathrm{M}, \mathrm{Al} / \mathrm{Ti} \quad 30$, toluene $d_{8} /$ $o$ difluorobenzene, $25{ }^{\circ} \mathrm{C}$ ): ${ }^{1} \mathrm{H}$ spectrum (a), ${ }^{19} \mathrm{~F}(\mathrm{~b}),{ }^{13} \mathrm{C}\left\{{ }^{1} \mathrm{H}\right\}$ (c), ${ }^{13} \mathrm{C}\left\{{ }^{19} \mathrm{~F}\right\}(\mathrm{d}),{ }^{13} \mathrm{C}$ selectively decoupled from $F_{\mathrm{a}}$ at $117.6 \mathrm{ppm}$ (e), ${ }^{13} \mathrm{C}$ selectively decoupled from $F_{\mathrm{b}}$ at $\delta \quad 120.0 \mathrm{ppm}$ (f). In (a), asterisks mark an admixture of dodecane in ${ }^{13} \mathrm{C} \mathrm{MAO}$; in (d) (f), some degradation products of $\mathbf{3 a}$.

intermediates, which are often detected in metallocene olefinpolymerization catalytsts. $^{7}$

In the absence of a monomer, the ion pair intermediates 3 are unstable even at low temperatures ( 10 to $25^{\circ} \mathrm{C}$ ) and slowly decompose via ligand transfer to $\mathrm{AlMe}_{3}$, to yield $\mathrm{LAlMe}_{2}$, as previously observed for related titanium catalysts. ${ }^{6,8}$ The

(8) The presence of at least two types of titanium(III) species in partially decomposed samples has also been detected by EPR (see SI). catalytic activity of complexes $\mathbf{3} \mathbf{a}$ and $\mathbf{3 b}$ was confirmed by the observation of Ti- $\left(\mathrm{CH}_{2}-\mathrm{CH}_{2}\right)_{n}-\mathrm{CH}_{3}$ signals arising upon injection of ethylene.

Both complexes $\mathbf{3} \mathbf{a}$ and $\mathbf{3 b}$ display $C_{2}$ symmetry, with singlets for equivalent vinyl $\mathrm{H}, \mathrm{CH}_{3}$, and $\mathrm{CF}_{3}$ groups and two singlets for two sorts of nonequivalent aryl- $F$ (Figure 1a,b and SI). The $\mathrm{Ti}-\mathrm{CH}_{3}$ group appears as a doublet superimposed on a singlet, due to the overlap of $\mathrm{Ti}^{-12} \mathrm{CH}_{3}(40 \%)$ and $\mathrm{Ti}^{-1}{ }^{13} \mathrm{CH}_{3}(60 \%)$ patterns (Figure 1a). Unlike the bis(phenoxyimine) titanium systems, ${ }^{6 c}$ no evidence of weak solvent (o-difluorobenzene) coordination has been detected for complexes of the type 3. In effect, they retain their apparent $C_{2}$ symmetry even at very low temperatures ( 10 to $85^{\circ} \mathrm{C}$, cf. SI), with no signs of any additional line broadening due to methyl group exchange between both accessible coordination sites of titanium. This enabled us to resolve the $\mathrm{Ti}^{13}{ }^{13} \mathrm{CH}_{3}$ signal of $\mathbf{3 a}$ in a ${ }^{13} \mathrm{C}\left\{{ }^{1} \mathrm{H}\right\}$ spectrum as a triplet at $\delta 126.6$ with a $7 \mathrm{~Hz}$ coupling constant (Figure 1). This coupling, which results from two ${ }^{19} \mathrm{~F}$ nuclei, is only seen for complex $\mathbf{3 a}$, whereas for $\mathbf{3} \mathbf{b}$ the $\mathrm{Ti}_{-}{ }^{13} \mathrm{CH}_{3}$ carbon signal appears as a clear singlet at $\delta 117.0$ (SI). Any conceivable interaction with coordinated $o$-difluorobenzene is thus ruled out, and the observed multiplicity is obviously due to intramolecular C,F coupling in 3a. Indeed, the $7 \mathrm{~Hz}$ splitting disappeared in a ${ }^{13} \mathrm{C}\left\{{ }^{19} \mathrm{~F}\right\}$ spectrum; moreover, selective ${ }^{19} \mathrm{~F}$ decoupling experiments identified the fluorine nuclei $\left(F_{\mathrm{b}}\right.$ at $\delta \quad 120.0$ in the ${ }^{19} \mathrm{~F}$ spectrum) as being responsible for the C,F coupling (Figure 1d f).

The origin of this coupling is not a priori clear. A possible explanation could be a weak $\mathrm{Ti} \mathrm{C} \mathrm{H} \cdot \mathrm{F}$ C hydrogen bonding similar to that reported by Chan and co-workers for catalytically inactive model $\mathrm{Zr}$ and Ti complexes. ${ }^{3 \mathrm{~b}, \mathrm{c}}$ Hydrogen bonding of this type might be possible also for complex $3 \mathbf{a}$, especially if one takes into account the proximity of $F_{\mathrm{b}}$ to the Ti-Me group, which is apparent from a heteronuclear ${ }^{19} \mathrm{~F},{ }^{1} \mathrm{H}$ NOE contact between these nuclei (SI). However, this coupling mechanism cannot explain why the value of the ${ }^{2 \mathrm{H}} J_{\mathrm{CF}}=7 \mathrm{~Hz}$ splitting in $\mathbf{3 a}$ is so much higher than that of ${ }^{1 \mathrm{H}} J_{\mathrm{HF}}$ (which cannot be observed at all).

Most consistent with such a geometry as well as with the observed effects on catalytic properties is the proposition

(9) After addition of several equivalents of ethylene at low tempera ture, $\mathbf{3 a}$ or $\mathbf{3 b}$ converted to the propagating "Ti polymeryl" species (cf. refs $6 \mathrm{~b}, \mathrm{c}$ and references therein). The $\mathrm{Ti}^{13} \mathrm{CH}_{2}$ Pol groups were found at $\delta 148.2\left(\mathrm{~d},{ }^{1} J_{\mathrm{CC}}\right.$ ca. $\left.30 \mathrm{~Hz}\right)$ in the case of $\mathbf{3 a}$ and 149.1 (broad) in the case of $3 \mathbf{b}$, respectively. Details will be given in future publications.

(10) This explanation assumes a through titanium coupling and is thus consistent with the observation that ${ }^{2} J_{\mathrm{CF}}$ values are greater than ${ }^{3} J_{\mathrm{CH}}$. "Through space" $\mathrm{F}-\mathrm{H}$ and $\mathrm{F}-\mathrm{C}$ couplings, on the other hand, have been observed in many cases where the interatomic distances do not exceed the respective van der Waals contact distances (i.e., $2.5 \AA$ for $\mathrm{F} \cdots \mathrm{H}$ vs $3.1 \AA$ for $\mathrm{F} \cdots \mathrm{C}$ ) and have been attributed to orbital interactions that transmit scalar couplings but do not cause net chemical bonding. ${ }^{11}$ A "through space" contribution to the observed F,C cou pling might also take place for $\mathbf{3 a}$. 


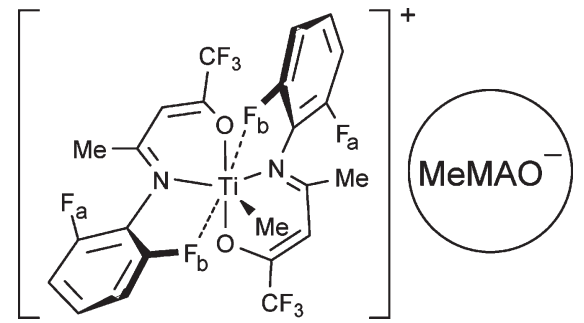

Figure 2. $\mathrm{Ti} \mathrm{F}$ interaction in complex 3a.

that the ligand framework in $\mathbf{3 a}$ is distorted (relative to that of its precursor 1a) so that two fluorine substituents of different aryl rings interact with the electron-deficient metal center, which thus becomes formally seven-coordinate (Figure 2). ${ }^{10}$ Such an interaction in complex $\mathbf{3 a}$ and in the propagating "Ti-polymeryl" species derived from it would most likely cause substantial encumbrance of chain transfer to aluminum (as well as of $\beta$-hydrogen elimination or

(11) (a) Xie, X.; Yuan, Y.; Kruger, R.; Broring, M. Magn. Reson. Chem. 2009, 47, 1024 1030. (b) Pogodin, S.; Rae, I. D.; Agranat, I. Eur. J. Org. Chem. 2006, 5059 5068. (c) Mele, A.; Salani, G.; Viani, F.; Bravo, P. Magn. Reson. Chem. 1997, 35, 168 174. (d) Gribble, G. W.; Olson, E. R.; Brown, J. H.; Bushweller, C. H. J. Org. Chem. 1993, 58, 16311634. (e) Hilton, J.; Sutcliffe, L. H. Progr. NMR Spectrosc. 1975, 10, 2739.

(12) (a) Karl, J.; Erker, G.; Frohlich, R. J. Am. Chem. Soc. 1997, 119, 11165 11173. (b) Schrock, R. R.; Adamchuk, J.; Ruhland, K.; Lopez, L. P. H. Organometallics 2003, 22, 5079 5091. (c) Ritter, T.; Day, M. W.; Grubbs, R. H. J. Am. Chem. Soc. 2006, 128, 1176811769. transfer to the monomer), due to increased steric hindrance and coordinative saturation at the metal center.

In conclusion, these studies bear evidence in favor of the interaction of $o-\mathrm{F}$ substituents with the metal center in an active living polymerization catalyst. Noncovalent interactions of this type have been reported to affect the catalytic activity of polymerization and metathesis catalysts ${ }^{12}$ and cannot be ruled out when discussing the origin of living polymerization behavior of $o$-fluorinated post-titanocene catalysts. In particular, the aryl-F..Ti interactions discussed are likely to favor the capability of $o$-F-substituted bis(enolatoimine) and structurally related bis(phenoxyimine) $\mathrm{Ti}$ catalysts to induce living olefin polymerization, via suppression of chain transfer and of $\beta$-hydrogen transfer processes.

Acknowledgment. The authors thank Dr. Dmitrii Babushkin, Dr. Nina Semikolenova, and Dr. Valentina Panchenko for the synthesis of ${ }^{13} \mathrm{C}-\mathrm{MAO}, \mathrm{Mr}$. Mykhailo Azarkh for EPR measurements, Mr. Ulrich Haunz and Ms. Anke Friemel for technical assistance with NMR measurements, and Prof. Hans-Herbert Brintzinger for helpful discussions. Financial support from the DFG and RFBR (grant Me 1388/9-1/10-03-91330) is gratefully acknowledged.

Supporting Information Available: Experimental techniques, NMR data, and spectra of the titanium intermediates. This material is available free of charge via the Internet at http://pubs.acs.org. 